\title{
Socio-demographic factors influencing Preventive Dental Behaviours in an Adult Dentate population: A questionnaire based survey.
}

\author{
Sachit Anand Arora' ${ }^{1}$, Amit Jayna ${ }^{2}$, Anil Sharma ${ }^{3}$, Mansi Atri ${ }^{4}$
}

Professor $^{1}$

Department of Periodontics

I.T.S Dental College, Hospital \& Research Centre

Greater Noida, Uttar Pradesh, (India).

Professor $^{2}$

Professor \& $\mathrm{Head}^{3}$

Department of Prosthodontics

I.T.S Dental College, Hospital \& Research Centre

Greater Noida, Uttar Pradesh, (India).

Senior Lecturer ${ }^{4}$

Department of Public Health Dentistry

I.T.S Dental College, Hospital \& Research Centre

Greater Noida, Uttar Pradesh, (India).

Article Info

Received: January 10, 2011

Review Completed: February 13, 2011

Accepted: March 17, 2011

Available Online: July, 2011

(c) NAD, 2011 - All rights reserved

\section{ABSTRACT:}

Good oral health can be achieved by preventive dental behaviours such as regular dental visits as well as practising adequate selfcare by means of proper and frequent tooth brushing methods.

OBJECTIVES: To correlate the influence of socio-economic parameters (occupation, education and income) according to modified Kuppuswamy's scale on preventive dental behaviours such as frequency of dental visits and tooth brushing with paste.

METHODS: A self-administered questionnaire based cross sectional survey was conducted to determine the influence of socio- economic status on Dental visits and frequency of tooth brushing in patients visiting the O.P.D ( Out Patient Department) at I.T.S Dental College, Greater Noida. A total of 327 patients from 18 to 74 years were included from both the genders. A fifteen item closed ended questionnaire was prepared, which had information regarding the Chief complaint along with Age, Gender, Socioeconomic Status, intervals of dental visits and frequency of brushing. Kuppuswamy's socioeconomic classification, which includes monthly income, education level and occupation, was used to classify the socioeconomic status (SES) of the patients.

RESULTS:There was no statistically significant difference reported between various levels of education, socio-economic status and gender when correlated with the frequency of dental visits. However, the results show that with increase in the level of education and socio-economic status the frequency of tooth brushing was positively correlated.

CONCLUSION: The results of our study suggest that groups with low education and socio-economic status are important targets to enhance dental preventive behaviours.

Key words: Socio-economic status, Dental visits, Tooth brushing, Education.

\section{INTRODUCTION}

Good oral health is an integral part of a general health. This can be achieved by a regular dental visits as well as practising meticulous self-care by means of proper and frequent tooth brushing methods. ${ }^{1}$ Socioeconomic factors have been linked with frequency of dental visits.Various studies have documented that people who seek regular dental visits have a better oral health than who do not visit

Email for correspondence:

arorasachitanand9@gmail.com or seek regular dental care., ${ }^{2,3}$ Frequency of dental visits has also been associated positively with more frequent tooth brushing. ${ }^{4}$ Tooth brushing with fluoridated tooth paste is an effective way of maintaining good oral hygiene when performed for an adequate duration of time. ${ }^{5}$ Appropriate adherence to tooth brushing regimens may alleviate certain common oral diseases such as chronic Periodontitis and dental caries. ${ }^{6}$ Various studies have found a correlation between socio- economic variables and tooth brushing practices. ${ }^{4,7,8,}$, Due to 
paucity of data, pertinent to this area, the current study was conducted to determine how socioeconomic variables areassociated with preventive dental behaviours (dental visits, frequency of brushing with toothpaste) among semi-urban population of Greater Noida (U.P) India.

\section{AIMS \& OBJECTIVES}

1. To correlate the influence of gender and socioeconomic parameters (occupation, education and income) according to modified Kuppuswamy's scale ${ }^{9}$ on Dental visits.

2. To assess the influence of gender and socioeconomic parameters on frequency of Tooth Brushing.

\section{MATERIAL \& METHODS}

A cross sectional survey was conducted to determine the influence of socio- economic status on dental visits and frequency of tooth brushing in patients visiting the O.P.D ( Out Patient Department) at I.T.S Dental College, Greater Noida. A total of 327 patients from 18 to 74 years were included from both the genders (Table-1). A fifteen item closed ended questionnaire was prepared, which had information regarding the Chief complaint along with Age, Gender, Socioeconomic Status, intervals of dental visits and frequency of brushing.Modified Kuppuswamy's socio-economic classification, which includes monthly income, education level and occupation, was used to classify the socio-economic status (SES) of the patients. In accordance with this classification, the socioeconomic status of the subjects was divided into five classes from class I to class $V$ shown in Table 2.In the questionnaire, information regarding frequency of dental visit was based on two pertinent questions. For the first question "is it your first visit to the dentist ". If the answer was yes the box against yes was ticked. If the answer was No a second round of Multiple choice question was asked "How often do u visit a dentist". The second question was divided into three intervals of dental visit.
a) 3-6 months
b) 6 months to one year
c) > one year.

The respondents were asked to tick the one appropriate answer out of the three choices given above. With regard to frequency of brushing, again two set of questions were asked. The first question "do u clean your teeth with brush and paste"?

If the respondent was using any other method of cleaning their teeth, the subject was excluded from the study; if the answer was Yes then a multiple choice question was asked regarding frequency of tooth brushing with paste "how many times do u brush your teeth with paste". The options given were
a. Never
b. Occasionally
c. Once in a day
d. Twice in a day
e. More than two times

The patient was again asked to tick the appropriate answer. The drafted questionnaire was pilot tested on twenty five patients to check the authenticity of the study, and the questionnaire was modified after expert advice.The subjects included in the pilot study were excluded from the main study.Data collected from the study was analysed statistically applying Chi-Square test at a significance level of $p<0.05$ using SPSS (version 13) software.

\section{RESULTS}

Out of 327 subjects, $113(34.5 \%)$ were females and 214 (65.4\%) were males (Table -1).Table-2 shows distribution of subjects according to the level of education. Table -3 shows distribution of subjects according to modified Kuppuswamy's scale of socioeconomic status.

\section{EDUCATION AND PREVENTIVE DENTAL BEHAVIOUR}

Out of 327 respondents in the study,33(10.09\%) of the total subjects were visiting a dental set up for the first time, 111 (33.94\%) visit between 3 to 6 months period,58(17.74\%)between 6 months to 1 year and $125(38.23 \%)$ of the subjects visit a dentist after more than 1 year interval. There was no statistically significant difference reported between various levels of education and the frequency of dental visits (Table-4, fig-1). 
When education was correlated with frequency of brushing, none of the subjects who had a professional education reported to never or occasionally brush their teeth. In the illiterate category 9 (13.04\%) subjects said they brush their teeth only occasionally and $7(10.14 \%)$ reported to never perform tooth brushing with paste. The results show that with increase in the level of education the frequency of tooth brushing also increased. This correlation was found to be highly statistically significant (Table-5, Fig-2).

\section{SOCIO-ECONOMIC STATUS AND PREVENTIVE DENTAL BEHAVIOUR}

The results show that there was no positive correlation between various classes of socioeconomic status and frequency of dental visits (Table-6, Fig-3).

Only $1(2.32 \%)$ subject in the upper and upper middle class reported to never perform tooth brushing with Toothpaste, rest all the subjects brushed their teeth at least once daily in this strata of socio-economic status.

Out of all the subjects, only 191(58.40\%) brushed with paste at least once daily and $14(4.28 \%)$ never brushed their teeth.A positive correlation was found between higher socio-economic status and increased frequency of tooth brushing in this study (Table-7, Fig-4).

\section{GENDER AND PREVENTIVE DENTAL BEHAVIOUR}

When gender was compared in accordance to frequency of dental visits more percentage of females 45(39.82\%) visit a dentist between 3 to six months than males 66 (30.85\%). However, this finding was not found to be statistically significant (Table- 8, Fig-5).

The result of this study showed that only $191(58.40 \%$ ) of the total subjects brushed once daily and statistical analysis revealed no significant differences between the genders for tooth cleaning frequency, though it was observed that greater percentage of males $132(61.68 \%)$ cleaned their teeth with paste at least once in a day in comparison with females 59(43.70\%) (Table-9, Fig-6).
TABLE-1

DISTRIBUTION OF SUBJECTS ACCORDING TO
GENDER

\begin{tabular}{lcc} 
GENDER & NO. OF PATIENTS & PERCENTAGE \\
\hline FEMALE & 113 & 34.5 \\
\hline MALE & 214 & 65.4 \\
\hline TOTAL & 327 & 100.00 \\
\hline
\end{tabular}

TABLE-2

DISTRIBUTION OF SUBJECTS ACCORDING TO EDUCATION

EDUCATION FREQUENCY PERCENTAGE

\begin{tabular}{lcc} 
ILLITERATE & 69 & 21.1 \\
\hline PRIMARY & 35 & 10.7 \\
\hline MIDDLE & 42 & 12.8 \\
\hline HIGH SCHOOL & 49 & 15.0 \\
\hline INTERMEDIATE & & \\
\hline AND DIPLOMA & 58 & 17.7 \\
\hline GRADUATE AND & & \\
\hline POST GRADUATE & 63 & 19.3 \\
\hline PROFESSIONAL & 11 & 3.4 \\
\hline TOTAL & 327 & 100.0
\end{tabular}

TABLE-3
DISTRIBUTION OF SUBJECTS ACCCORDING TO SOCIO-ECONOMIC STATUS

\begin{tabular}{lcc}
$\begin{array}{l}\text { SOCIOECONOMIC } \\
\text { STATUS }\end{array}$ & $\begin{array}{c}\text { NO. OF } \\
\text { PATIENTS }\end{array}$ & PERCENTAGE \\
UPPER & 17 & 5.2 \\
\hline UPPER MIDDLE & 43 & 13.1 \\
\hline LOWER MIDDLE & 56 & 17.1 \\
\hline UPPER LOWER & 139 & 42.5 \\
\hline LOWER & 72 & 22.0 \\
\hline TOTAL & 327 & 100.00 \\
\hline
\end{tabular}


TABLE-4

DENTAL VISIT FREQUENCY DISTRIBUTION OF SUBJECTS ACCORDING TO EDUCATION

\begin{tabular}{|c|c|c|c|c|c|}
\hline \multirow{3}{*}{ EDUCATION } & \multicolumn{4}{|c|}{ DENTAL VISIT } & \multirow[b]{2}{*}{ TOTAL } \\
\hline & $\begin{array}{l}\text { FIRST } \\
\text { TIME }\end{array}$ & $\begin{array}{r}(\mathrm{N}) 3-6 \\
\text { MONTHS }\end{array}$ & $\begin{array}{r}6 \text { MONTHS- } \\
1 \text { YEAR }\end{array}$ & $>1$ YEAR & \\
\hline & $\%(\mathrm{~N})$ & $\%(\mathrm{~N})$ & $\%(\mathrm{~N})$ & $\%(\mathrm{~N})$ & $(\mathrm{N})$ \\
\hline ILLITERATE & $11.59(8)$ & $28.98(20)$ & $11.60(8)$ & $47.83(33)$ & 69 \\
\hline PRIMARY & $11.42(4)$ & $37.14(13)$ & $17.14(6)$ & $34.28(12)$ & 35 \\
\hline MIDDLE & $16.67(7)$ & $33.34(14)$ & $23.80(10)$ & $26.19(11)$ & 42 \\
\hline HIGH SCHOOL & $4.09(2)$ & $42.85(21)$ & $14.29(7)$ & $38.77(19)$ & 49 \\
\hline INTERMEDIATE \& DIPLOMA & $5.17(3)$ & $37.94(22)$ & $18.96(11)$ & $37.93(22)$ & 58 \\
\hline GRADUATE \&POST GRADUATE & $11.12(7)$ & $30.15(19)$ & $22.23(14)$ & $36.50(23)$ & 63 \\
\hline PROFESSIONAL & $18.18(2)$ & $18.18(2)$ & $18.19(2)$ & $45.45(5)$ & 11 \\
\hline TOTAL & $10.09(33)$ & $33.94(111)$ & $17.74(58)$ & $38.23(125)$ & 327 \\
\hline
\end{tabular}

$p=0.587$ NOT SIGNIFICANT

\section{TABLE-5}

TOOTH CLEANING FREQUENCY DISTRIBUTION ACCORDING TO EDUCATION

\begin{tabular}{|c|c|c|c|c|c|c|}
\hline \multirow{3}{*}{ EDUCATION } & \multicolumn{5}{|c|}{ FREQUENCY OF CLEANING TEETH } & \multirow{3}{*}{$\begin{array}{r}\text { TOTAL } \\
\text { (N) }\end{array}$} \\
\hline & ONCE & TWICE & $\begin{array}{r}>\text { TWO TIMES } \\
\text { A DAY } \\
\end{array}$ & $\begin{array}{r}\text { OCCASIO- } \\
\text { NALLY } \\
\end{array}$ & NEVER & \\
\hline & $\%(\mathrm{~N})$ & $\%(\mathrm{~N})$ & $\%(\mathrm{~N})$ & $\%(N)$ & $\%(\mathrm{~N})$ & \\
\hline ILLITERATE & $47.84(33)$ & $14.49(10)$ & $14.49(10)$ & $13.04(9)$ & $10.14(7)$ & 69 \\
\hline PRIMARY & $60.00(21)$ & $8.57(3)$ & $14.28(5)$ & $14.28(5)$ & $2.87(1)$ & 35 \\
\hline MIDDLE & $52.38(22)$ & $16.66(7)$ & $9.52(4)$ & $16.66(7)$ & $4.25(2)$ & 42 \\
\hline HIGH SCHOOL & $69.34(33)$ & $11.90(5)$ & $14.28(7)$ & $6.12(3)$ & $2.04(1)$ & 49 \\
\hline INTERMEDIATE\& DIPLOMA & $72.41(42)$ & $20.68(12)$ & $1.72(1)$ & $1.72(1)$ & $3.44(2)$ & 58 \\
\hline GRADUATE \&POST GRADUATE & $60.31(38)$ & $34.92(22)$ & $3.17(2)$ & $0(0)$ & $1.58(1)$ & 63 \\
\hline PROFESSIONAL & $18.18(2)$ & $63.63(7)$ & $18.18(2)$ & $0(0)$ & $0(0)$ & 11 \\
\hline TOTAL & 58.40 (191) & $20.18(66)$ & $9.48(31)$ & $7.06(25)$ & $4.28(14)$ & 327 \\
\hline
\end{tabular}

$p=0.000$ HIGHLY SIGNIFICANT 
TABLE-6

DENTAL VISIT FREQUENCY DISTRIBUTION ACCORDING TO SOCIO-ECONOMIC STATUS

\begin{tabular}{|c|c|c|c|c|c|}
\hline \multirow{4}{*}{ SOCIO-ECONOMIC STATUS } & \multicolumn{4}{|c|}{ DENTAL VISIT } & \multirow{3}{*}{ TOTAL } \\
\hline & FIRST & (N)3-6 & 6 MONTHS- & $>1$ YEAR & \\
\hline & TIME & MONTHS & 1YEAR & & \\
\hline & $\%(\mathrm{~N})$ & $\%(\mathrm{~N})$ & $\%(\mathrm{~N})$ & $\%(\mathrm{~N})$ & $(\mathrm{N})$ \\
\hline UPPER & $11.76(2)$ & $23.54(4)$ & $11.76(2)$ & $52.94(9)$ & 17 \\
\hline UPPER MIDDLE & $4.65(2)$ & $34.88(15)$ & $23.25(10)$ & $37.22(16)$ & 43 \\
\hline LOWER MIDDLE & $8.92(5)$ & $35.72(20)$ & $23.22(13)$ & $32.25(18)$ & 56 \\
\hline UPPER LOWER & $11.51(16)$ & $35.9(50)$ & $17.26(24)$ & $35.49(45)$ & 139 \\
\hline LOWER & $11.11(8)$ & $30.55(22)$ & $12.50(9)$ & $45.84(33)$ & 72 \\
\hline TOTAL & $10.09(33)$ & 33.99 (111) & $17.70(58)$ & $38.22(125)$ & 327 \\
\hline
\end{tabular}

$p=0.717$ NOT SIGNIFICANT

TABLE-7

TOOTH CLEANING FREQUENCY DISTRIBUTION ACCORDING TO SOCIO-ECONOMIC STASTUS

\begin{tabular}{|c|c|c|c|c|c|c|}
\hline \multirow{3}{*}{ SOCIO-ECONOMIC STATUS } & \multicolumn{5}{|c|}{ FREQUENCY OF CLEANING TEETH } & \multirow{3}{*}{$\begin{array}{r}\text { TOTAL } \\
\text { (N) }\end{array}$} \\
\hline & ONCE & TWICE & $\begin{array}{r}>\text { TWO TIMES } \\
\text { A DAY }\end{array}$ & $\begin{array}{l}\text { OCCASIO- } \\
\text { NALLY }\end{array}$ & NEVER & \\
\hline & $\%(\mathrm{~N})$ & $\%(\mathrm{~N})$ & $\%(\mathrm{~N})$ & $\%(\mathrm{~N})$ & $\%(\mathrm{~N})$ & \\
\hline UPPER & $52.94(1)$ & $41.17(7)$ & $5.88(1)$ & $0(0)$ & $0(0)$ & 17 \\
\hline UPPER MIDDLE & $67.44(29)$ & $27.90(12)$ & $2.32(1)$ & $0(0)$ & $2.32(1)$ & 43 \\
\hline LOWER MIDDLE & $71.42(40)$ & $10.71(6)$ & $5.35(3)$ & $7.14(4)$ & $5.35(3)$ & 56 \\
\hline UPPER LOWER & $32.37(75)$ & $22.30(31)$ & $10.79(15)$ & $9.35(13)$ & $3.59(5)$ & 139 \\
\hline LOWER & $52.77(38)$ & $13.88(10)$ & $15.27(11)$ & $11.11(8)$ & $6.94(5)$ & 72 \\
\hline TOTAL & $58.40(191)$ & $20.18(66)$ & $9.48(31)$ & $7.64(25)$ & $4.28(14)$ & 327 \\
\hline
\end{tabular}

$p=0.035$ SIGNIFICANT 
TABLE-8

DENTAL VISIT FREQUENCY DISTRIBUTION ACCORDING TO GENDER

\begin{tabular}{lrrrrrr} 
& \multicolumn{5}{c}{ DENTAL VISIT } & \\
\cline { 2 - 5 } GENDER & FIRST & $3-6$ & $6-1$ YEAR & $>1$ YEAR & TOTAL \\
& TIME & MONTHS & & & \\
\cline { 2 - 5 } & $\%(\mathrm{~N})$ & $\%(\mathrm{~N})$ & $\%(\mathrm{~N})$ & $\%(\mathrm{~N})$ & $(\mathrm{N})$ \\
\hline FEMALE & $12.40(14)$ & $39.82(45)$ & $17.70(20)$ & $30.08(34)$ & 113 \\
\hline MALE & $8.88(19)$ & $30.85(66)$ & $17.75(38)$ & $42.52(91)$ & 214 \\
\hline TOTAL & $\mathbf{3 3}$ & $\mathbf{1 1 1}$ & $\mathbf{5 8}$ & $\mathbf{1 2 5}$ & $\mathbf{3 2 7}$ \\
\hline
\end{tabular}

$\mathrm{P}=0.130$ NOT SIGNIFICANT

TABLE-9

TOOTH CLEANING FREQUENCY DISTRIBUTION ACCORDING TO GENDER

\begin{tabular}{lrrrrrr}
\multicolumn{7}{c}{ FREQUENCY OF CLEANING TEETH } \\
\cline { 2 - 6 } GENDER & ONCE & TWICE & $\begin{array}{r}\text { >TWO TIMES } \\
\text { A DAY }\end{array}$ & $\begin{array}{r}\text { OCCASIO- } \\
\text { NALLY }\end{array}$ & NEVER & TOTAL \\
\cline { 2 - 6 } & $\%(\mathrm{~N})$ & $\%(\mathrm{~N})$ & $\%(\mathrm{~N})$ & $\%(\mathrm{~N})$ & $\%(\mathrm{~N})$ & $(\mathrm{N})$ \\
\cline { 2 - 7 } FEMALE & $43.70(59)$ & $22.12(25)$ & $12.38(14)$ & $10.61(12)$ & $2.65(3)$ & 113 \\
\hline MALE & $61.68(132)$ & $19.15(41)$ & $7.94(17)$ & $6.07(13)$ & $5.14(11)$ & 214 \\
\hline TOTAL & $58.40(191)$ & $20.18(66)$ & $9.48(31)$ & $7.64(25)$ & $4.28(14)$ & 327 \\
\hline
\end{tabular}

$p=0.194$ NOT SIGNIFICANT
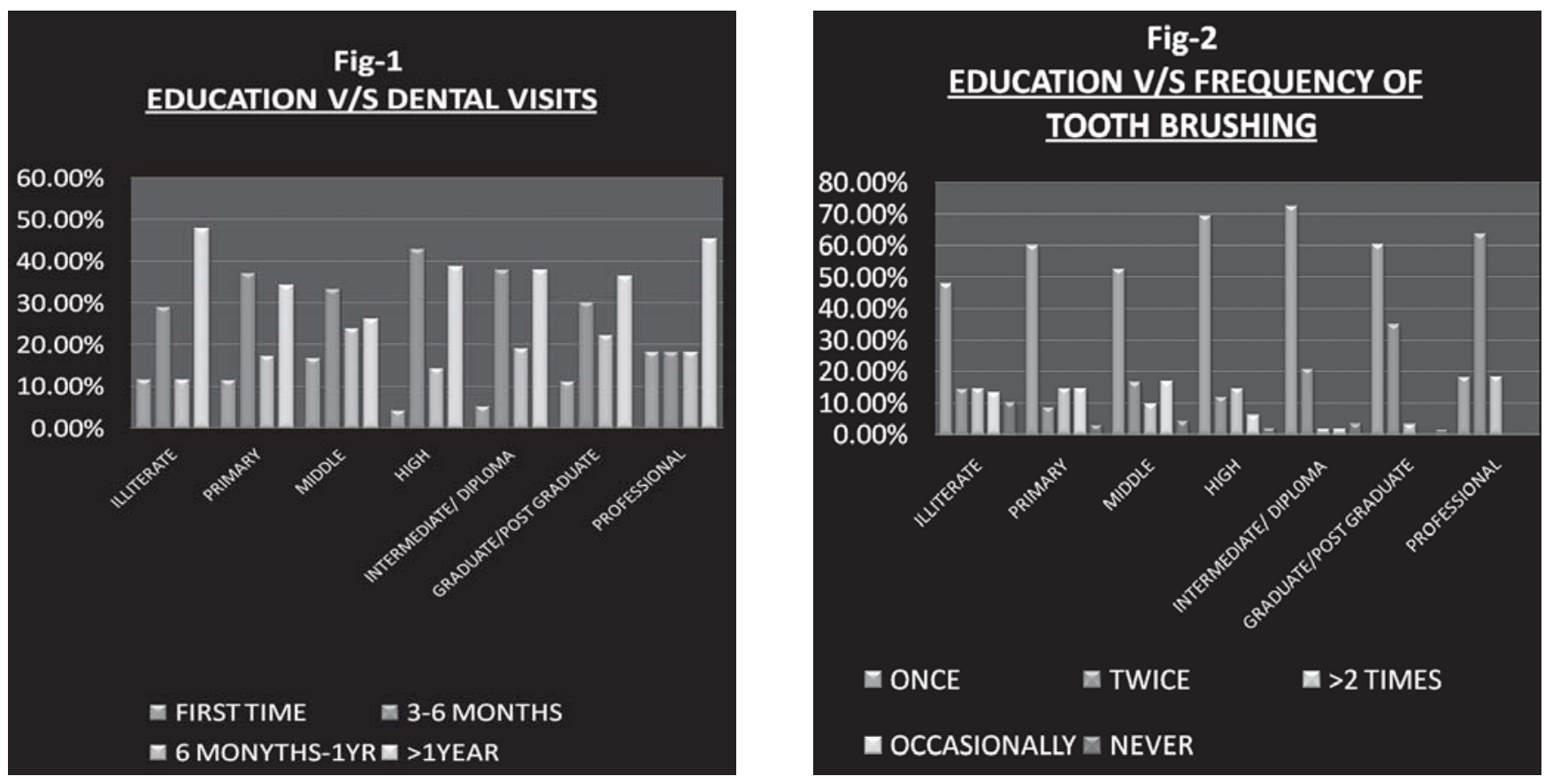

| 488 | IJDA, 3(2), April-June, 2011 

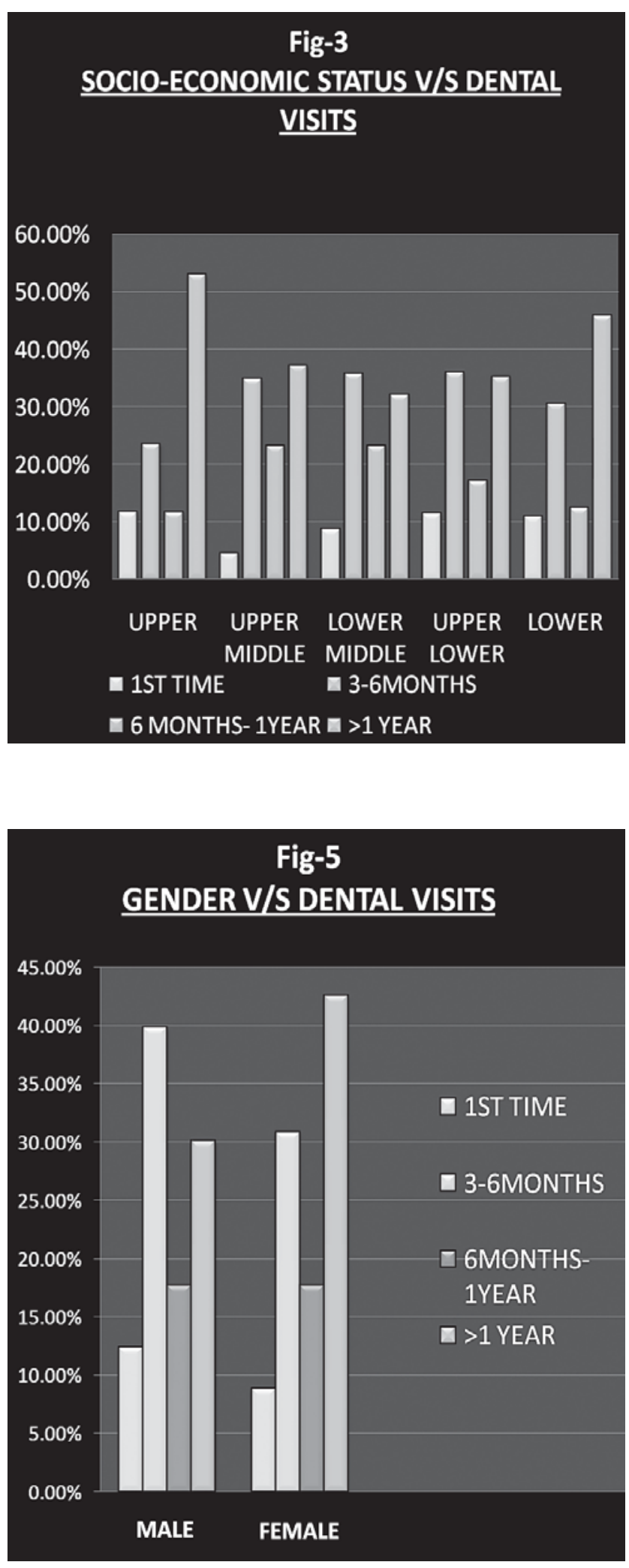
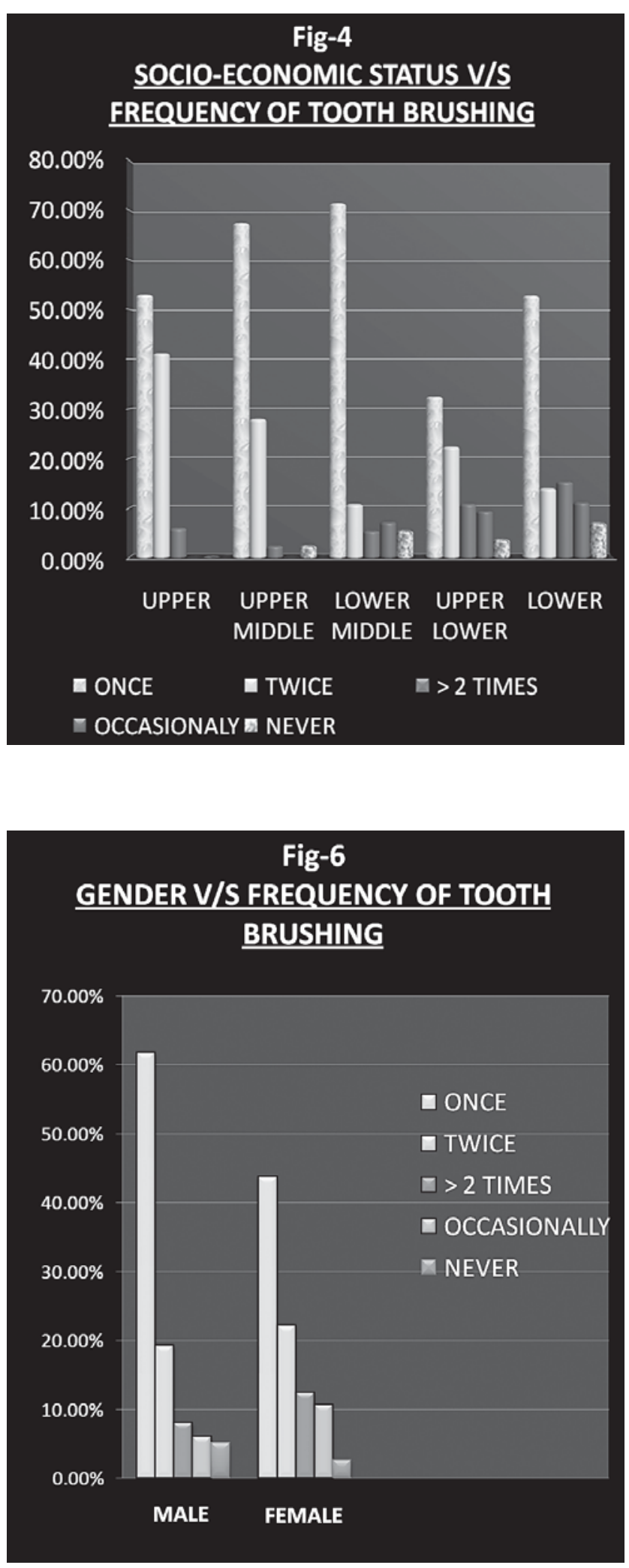


\section{DISCUSSION}

In light of limitation of past studies and scarcity of data we sought to examine the relations between two preventive dental behaviours (dental visits, frequency of tooth brushing) and socio- economic and demographic variables in a sample of residents of a defined geographic area. This paper focuses on describing and understanding correlation among socio-demographic factors and preventive dental behaviours.

\section{DENTAL VISITS}

A critical step in meeting the oral health care needs in any socio-economic strata, whether preventive or restorative is a dental visit. The results show that among the dentate adults no disparity was found between respondents of various levels of education and socioeconomic status when correlated with frequency of dental visits. This finding was not consistent with other studies, which have reported that people with higher education and socio-economic status are likely to visit a dentist more frequently. ${ }^{10,11,12}$ However, findings of our study show discouraging trends that only $17.74 \%$ of the subjects tend to visit a dentist between 6 months to 1 year period and more than one-third $(38.23 \%)$ visit a dentist not before a year. The plausible reason suggested by the authors could be that there are no large - scale community dental health education programmes in this area, and also people tend to visit a dental set up only in cases of emergencies and not for preventive dental care needs. Lack of public transport in this area could be another reason for not making frequent dental visits. Researchers have reported that traumatic dental experiences in the past ${ }^{13}$, family influences and high general fear level could also influence a dental visit. The relationship between these parameters and dental visits need to be addressed in future studies.

\section{FREQUENCY OF BRUSHING}

Despite the importance of tooth brushing (with toothpaste) to dental care, no studies have examined the dependent and independent variables associated closely with oral hygiene practices among this group of population. This study was based on the tenant that socio-demographic factors influence frequency of tooth brushing.
To prevent dental problems and diseases, the American Dental Association and other organisations recommend that adult dentate population should brush and floss their teeth at least once daily. ${ }^{14,15}$

Women are more likely to than men to perform frequent tooth brushing. ${ }^{16,17,18,19}$ However, in our study no statistical significance was found between the two genders. Researchers have documented that tooth brushing with paste is the easiest and the most effective way of controlling plaque. ${ }^{20,21}$ The findings from our study show that percentage of persons brushing at least once in a day was higher among subjects with increased levels of education and socioeconomic status. This finding was consistent with other studies. ${ }^{16,20,22,23,24,25,26}$ These findings, with the fact that brushing with paste is inexpensive, suggest that cultural differences (differing beliefs, attitudes, knowledge, and traditions) are more important than financial differences in explaining the impact of socio-economic status on frequency of tooth brushing. ${ }^{12}$

The results of our study suggest that groups with low education and socio-economic status are important targets to enhance dental preventive behaviours.

Community based preventive programmes need to be attempted to integrate health systems in this area of the state of Uttar Pradesh (India); strengthening and expanding oral health activities targeting people of lower socio-economic strata. Promoting the use of alternate dental services such as mobile dental service to reach the needy and the inaccessible remote areas is the need of the hour.

The research data from this study may provide a framework for further studies to determine how preventive dental behaviours such as dental visit and tooth brushing frequency can be linked strongly to socio-economic and demographic variables.

\section{STUDY LIMITATIONS}

There are certain lacunae in this study although it does not undermine its methodological design. As with any survey involving a self- administered questionnaire, this study was prone to over reporting of socially desirable answers and under reporting undesirable ones. 
The representative study group may not be extrapolated to other population groups in India. However, this group of study subjects do represent an important sub- group of population showing undesirable preventive dental behaviours.

\section{CONCLUSION}

Our study results indicate that socioeconomic variables such as education, occupation and income are associated strongly with frequency of tooth brushing with paste; however same correlation was not found with respect to dental visits. Since people from lower socio-economic status brushed their teeth less frequently than their higher counterparts, dental health education programmes need to be targeting this strata of population to enhance and improve their preventive dental behaviours.

\section{REFERENCES}

1. National Institute of Dental and Craniofacial Research, Oral Health in America: A report of the Surgeon General. Rockville, Md.: US Public Health Service, Department of Health and Human Services; 2000.

2. Newman JF, Gift HC. Regular pattern of preventive dental services: a measure of access. SocSci Med 1992; 35:997-1001.

3. Tickle $M$, Williams $M$, Jenner $T$, Blinkhorn $A$. The effects of socioeconomic status and dental attendance on dental caries experience, and treatment patterns in5-year old children. Br Dent J 1999; 186: 135-137.

4. Al-Shammari KF, Al-Ansari JM, Al-Khabbaz AK, Dashti A, Honkala EJ. Self-reported oral hygiene Habits and oral health problems of Kuwaiti adults. Med PrincPract 2007; 16(1):15-21.[Medline]

5. Fischman SL. The history of oral hygiene products: how far have we come in 6000 years? Periodontol 2000 .1997; 15: 7-14.

6. Koerber A, Burns JL, Berbaum M, et al. Tooth brushing patterns over time in at-risk metropolitan AfricanAmerican 5th-8th graders. J Public Health Dent 2005; 65(4):240-243.[Medline]

7. Villalobos-Rodelo JJ, Lau-Rojo L, Ponce de León-Viedas MV, Ver-dugo-Barraza L, Valle- Villaseñor JF, Guzmán-Fonseca TJ. Associated factors to tooth brushing practices in schoolchildren [in Spanish]. Rev MexPediatr 2006; 73(4):167-171.

8. Jamieson LM, Koopu PI. Exploring factors that influence child use of dental services and toothbrushing in New Zealand.Community Dent Oral Epidemiol 2006;34(6):410418.[Medline]

9. D. Mishra, H.P. Singh. Kuppuswamy's socioeconomic status scale- A revision. Indian J Pediatr2003; 70(3): 273-274
10. Macek M D, Cohen I, Reid BC, Manski R J.Denatl visits among older U.S adults, 1999:The rule of dentition status and cost. J Am Dent Assoc 2004; 135; 1154-1162.

11. Jenson K. Dental care practices and socio-economic status in Denmark. Community Dent Oral Epidemiol. 1974; 2:273281.

12. Ronis DL, Lang WP, Passow E. Tooth Brushing, Flossing, and Preventive Dental Visits by Detroit- area Residents in Relation to Demographic and Socio-economic Factors

13. Bernstein DA, Kleinknecht RA, Alexander LD. Antecedents of dental fear. J Public Health Dent 1979; 39: 113-24.

14. American Dental Association. Wake up to prevention for the smile of a lifetime. J Am Dent Assoc 1988; 116: 6-13.

15. National Institute of Health. Treatment for sound teeth. Washington, DC: US Government Printing Office, 1991; NIH pub no 91-3245.

16. Swank ME, Vernon SW, Lairson DR. Patterns of preventive dental behaviours, Public Health Rep 1986; 101: 175-184.

17. Chen M,Robinson L.Preventive dental behaviour in families: a national survey. J Am Dent Assoc 1982; 105:43-46.

18. Heleo LA. Aora LE, Soggard J.Dental practices in Norwegian adults. Community Dent Oral Epidemiol 1982; 10:308-312.

19. Schurs AH, Duivenvoorden HJ Velzen SK, Verhage F. Differentiating regular from irregular dental attenders of either sex by linear desciminant analysis. Community Dent Oral Epidemiol 1983; 11:43-49.

20. Lang NP, Cumming BR, Loe H. Tooth brushing frequency as it relates to plaque development and gingival health. $J$ Periodontol 1973; 44: 396-405.

21. Koivusilta L, Honkala S, HonkalaE, Rimpela“ A.Tooth brushing as part of the adolescent lifestyle predicts education level. J Dent Res2003; 82: 361-366.

22. Honkala S, Honkala E, Rimpela“ A, Vikat A. Oral hygiene instructionsand dietary sugar advice received by adolescents in 1989 and 1997. Community Dent Oral Epidemiol 2002; 30: 124-132.

23. Kumar S, Panwar J, Vyas A, Sharma J, Goutham B, Duraiswamy $P$, Kulkarni $S$. Tooth cleaning frequency in relation to socio-demographic variables and personal hygiene measures among school children of Udaipur district, India. Int J Dent Hyg 2011; 9: 3-8.

24. Bonito AJ, lannacchione V, Jones S, Stuart C. The impact of prepaid dental care on dental utilization and oral health. Research Triangle Park, NC: Research Triangle Institute, 1986.

25. Peterson PE, Pederson KM. Socioeconomic demand model for dental visits. Community Dent Oral Epidemiol 1984; 12:361-365.

26. Chen M, Stone DB.Tooth brushing, flossing, and dental visits in relation to socioeconomic characteristics of white American families. Community Dent Oral Epedimiol 1983; 11: 325-332. 